\title{
Iodine waters
}

\section{Munteanu Constantin ${ }^{1}$, Iliuta Alexandru ${ }^{2}$ ${ }^{1}$ Institutul Naţional de Recuperare, Medicina Fizica şi Balneoclimatologie ${ }^{2}$ S.C. BIOSAFETY SRL-D}

Iodine mineral waters are found especially in sub-Carpathian region, also in regions with Salif deposits. Waters are currently used iodine in drinking cure for chaps and Basedow. Are also indicated in balneology. Iodine water containing at least $1 \mathrm{mg} \backslash \mathrm{L}$, there is pure iodine is usually given the nature of other types of mineral waters further: sodium chlorinated water (Bazna $(50-70 \mathrm{mg}$ iodine / 1), Baile Govora (50 - $70 \mathrm{mg} / \mathrm{1}$ ), Bălțăteşti (4-5 mg / 1), salted Monteoru (30 mg / 1), mine) water mixed alkaline chlorination, sulphate, which are indicated for crenoterapie (hypo or isotonic to the bathrooms Olăneşti or Călimăneşti-Căciulata).

Iodine content of the water adds effects that broaden the indications for treatment. Iodine in water comes from sedimentary rocks and is home of former sea flora and fauna. Waters contain iodine and are used in internal treatment Olanesti meet in bathrooms (Sources: 5, 7, 8, 10, 11, 14, 19) and Călimăneşti to (6.8 Sources Pause) Cozia (1.3 Springs) . Abroad mineral iodine is at $\mathrm{Bad}$ Tolz, Bad Wiessee (Germany); Ciz, Luhacovice Lazne (CSR), Busko, (Poland), Bad Goisern (Austria); Salsomagiore, Castrocaro Agnano, Acircale, Salice (Italy). Groundwater salt concentration, iodine is found in high concentration (40-70 $\mathrm{mg} / 1)$.

Concentrated salt-iodine mineral water is used only in external cure. In crenoterapie intake of iodine in the thyroid contributes to its storage, as indicated in thyroid and ovarian endocrine disorders, which are adauaga and secretory stimulating effects on congestion and digestive mucosa. Although the amount of iodine is reduced by biological activity is remarkable.

Because of its ability to dilate blood vessels, thus facilitating movement chronically inflamed areas, facilitates the process of resorption and help improve local degenerative lesions. Moreover, it stimulated the body's defense capacity, thus improving the effective means of reducing the intensity of inflammatory processes. Also, through the direct intervention of iodine in improving cellular respiration, improves their resistance to aggression and inflammatory factors.

Due to the properties described, iodine waters are indicated for the treatment of chronic osteoarticular diseases, where the maximum effect is achieved by associating the internal hydro external cure. Iodine is present in low concentrations numerous mineral springs which are used in internal treatment. Ingested with mineral water, iodine exerts its farmacodina-small lymphoid tissue due to its concentration in the thyroid and liver.

The digestive mucosa congestion and stimulating exercise effect secretions. Thyroid function is particularly influenced by internal treatment with iodine mineral waters. Water treatment with iodine is shown in hipofuncții thyroid iodine deficient or iodine hipofunctii loss, and metabolic diseases with atherosclerosis, gout and hyperuricemia in.

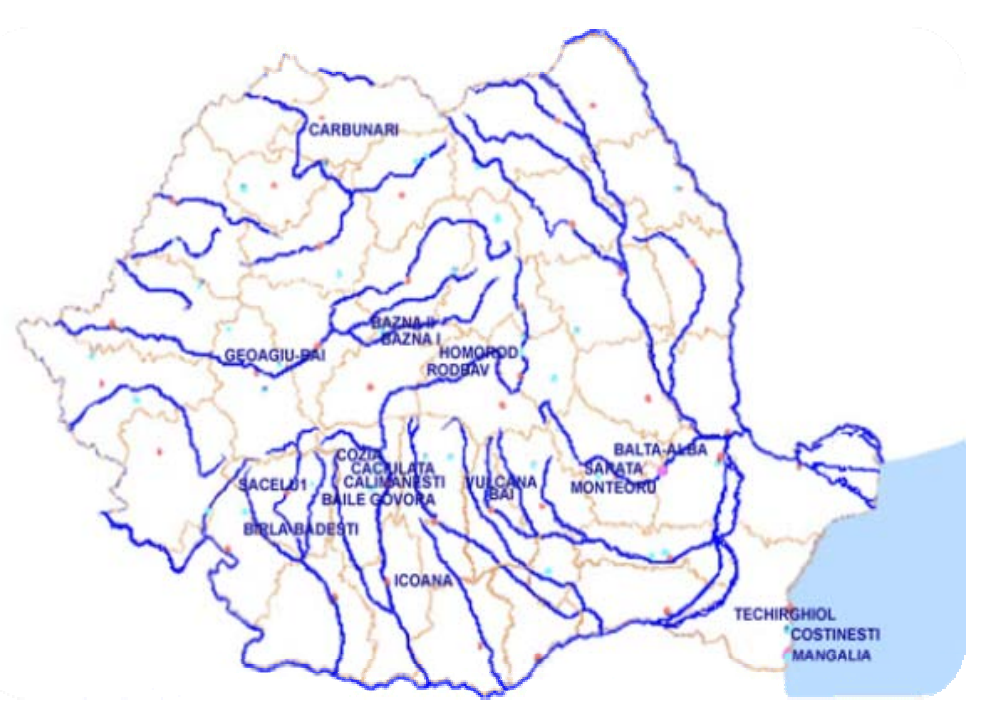


The external treatment (chlorinated bath water mixed sodium and iodine) iodule peripheral vasodilator effect antifungal effects in the skin and appendages.

Are indicated in patients with peripheral atherosclerosis or general, in patients with uric artitra and in patients with fungal skin disease. Salt-iodine baths are indicated in degenerative rheumatic diseases in rheumatism abarticulare or peripheral neurological diseases. By influencing metabolic reactions, clean hydromentioned is useful in the treatment of diseases such as gout and chronic poisoning with mercury and lead.

Also, by stimulating the uptake and degradation of cholesterol in arterial walls, iodine waters slow the progression of lesions ateroscle-pink. Mineral baths have a special contribution in improving the clinical manifestations of disease in that the rheumatism, circulatory, nervous, gynecological and dermatological. Iodine and other minerals contained in therapeutic bath are absorbed into the skin where they are gradually released into peripheral circulation.

On its obvious improvement occurs, due to dilatation of blood vessels deeper layers of skin and skeletal muscle neighborhood. By reducing resistance in these vessels an object thrown in front of the circulating blood volume with each cardiac contraction, blood pressure lowering is found environments.

However, there are indirect improvement of heart and vessel traffic cardiac oxygen consumption, parasitic skin affections (pityriasis verzicolor), mineral iodine has been effective in improving until complete healing of skin lesions. By stimulating local circulation and reduce inflammatory processes, iodine occurs in lower genital chronic congestive phenomena (prostatitis and chronic metroanexite). Also intervening in restoring cellular structures and to improve nerve management, hydro-iodine diet facilitates peripheral nervous system tone affected by certain chronic diseases. Rheumatic diseases also benefit from the therapeutic effects of iodine baths. The most famous resorts where you can practice these baths are: Vulcan Govora Bazna, Sarata-Monteoru, CalimanestiCăciulata.

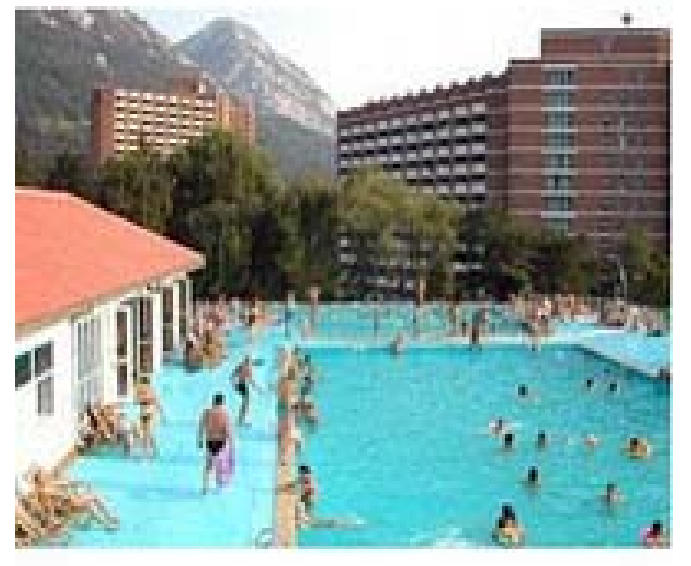

State with iodide Mineral Complex (for internal cures): Baile Olanesti CalimanestiCaciulata, Carei;

State with iodide Mineral Salt (for external cures): Baile Govora Bazna, Baltatesti, Sacelu, Salt Monteoru, horseshoes, mine;

\section{Olanesti Bai}

Geographic area: Skull Mountains - Valcea Subcarpatii

Type area: mountain basin / river / spring: the confluence of the Tisza Olanesti

Location: Mv. Wind and stack (N) - Cut Stone Hills (919m alt), Glod (NV), Tisa (V), Budestii (SV), Plaiul Miron (E)

\section{Conditions:}

- Digestive (hypoacid chronic gastritis, chronic constipation, chronic colitis)

- hepatobiliary (biliary dyskinesia, chronic cholecystitis not calculated or computer, disorders after liver surgery, chronic hepatitis, chronic pancreatitis)

- respiratory (respiratory dry climbing, people exposed to noxious professional people with common microbial or viral pneumopathies, allergic asthma, chronic bronchitis and traheobronsitele, bronchiectasis)

- Metabolic and nutrition disorders (diabetes mellitus, hyperuricaemia states of hiperlipezii, obesity)

- ENT diseases (chronic laryngitis, allergies naso-sinus)

- dermatology (psoriasis, ichtioze early, keratodermii, eczema and chronic hives, 
neurodermatitis, seborrheic dermatitis, acne, pyoderma) and degenerative

- rheumatic abarticulare

- neurasthenia accompanied by insomnia

- recovering from acute and chronic infectious diseases internal treatment: to cure inner-springs are given $3,5,7,8,9,10,11,12$, $14,19,24$ in-chronic stomach and intestine, chronic liver disease and kidney disease, biliary and urinary tract, skin diseases.

Internal cure:

-for internal cure are indicated springs 3,5 , $7,8,9,10,11,12,14,19,24$ in

-chronic stomach and bowel, and chronic liver disease, biliary diseases kidney and urinary tract, skin diseases.

\section{Calimanesti-Caciulata}

Geographic area: Skull Mountain, Cozia Type

area: mountain

basin / river / stream: Olt, spring out of the rocks Caciulata Pisorea Hill Location: Plaiul Frasinet (another 999m) Pisorea Deal

\section{Conditions:}

- external cure diseases of the digestive tract associated with musculoskeletal disorders, the cardiovascular system (hypertonic disease with maximum up to $17-18 \mathrm{~cm}$ ), peripheral circulation disorders, gynecological

- diseases of the digestive tract (hypoacid chronic gastritis, chronic constipation, chronic colitis)

- - hepatobiliary (biliary dyskinesia, chronic cholecystitis not calculated or computer, liver disorders after surgery (cholecystectomy), chronic hepatitis, chronic pancreatitis))

- Renal and urinary urinary (or unoperated renalaoperata stones, urinary stones, chronic pyelonephritis, urinary infections, chronic glomerulonephritis stabilized)

- Metabolism and nutrition (diabetes mellitus, hyperuricaemia states of hiperlipemii, obesity)

- rheumatic degenerative (cervical, dorsal, lumbar arthrosis, poliarthrosis)

- rheumatic inflammatory (allergic states joints after acute articular rheumatism or infections after outbreak)

- rheumatic abarticulare (tendinosis, tendomioze, tendoperiostoze, scapulohumeral periarthritis)

- traumatic (post-traumatic joint redori, states after operations on muscles, bones and joints, states as sprains, dislocations and fractures)

- $\quad$ peripheral neurological (paresis, states after polio)

- respiratory (breathing people exposed to pollutants, microbial or viral, allergic asthma, bronchitis and chronic tracheobronchitis, bronchiectasis)

- associated

(gynecology, otorhinolaryngology, dermatology, cardiovascular, endocrine, asthenic neurosis, diseases)

- Sulphur baths, carbonic acid baths and artificial bubble. 


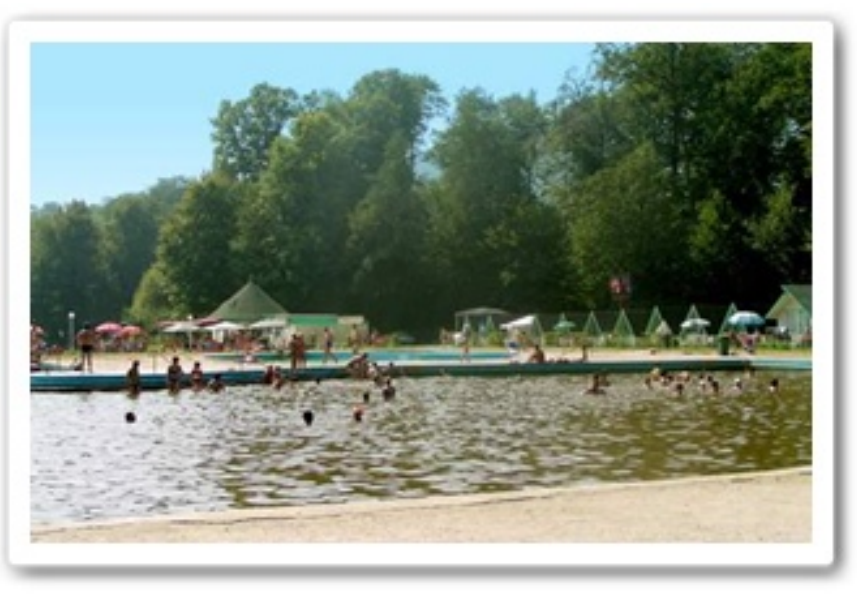

Băile Govora

http://www.bailegovora.ro

Geographic area: Subcarpatii Valcea area

Type: hill

basin / river / stream: Swing

Location: between hills Piscupia $(\mathrm{N})$, fried $(\mathrm{N})$, Frasinet (S), Curaturile (S), Zapodul (S), Bodeanca (E)

External cure:

-musculoskeletal disorders, endocrine hypofunction, gynecological, with peripheral and central nervous system (light paresis and minor sequelae after polyneuropathies, sequelae after poliomyelitis sequelae late after parapareze hemiparesis after 2 years of onset), dermatology ( chlorine sulphurous waters), peripheral circulatory disorders, chronic ganglion (iodine chlorine water), chronic poisoning with mercury, arsenic, bismuth

-respiratory (rhinitis, pharyngitis, laryngitis, bronchitis with hiposecretie (iodine), with hypersecretion (sulfur) in which case water is diluted to lower concentrations irritating before, people exposed to respiratory hazards, people with common

-microbial or viral pneumopathies, allergic asthma, chronic traheobronsitele, bronchiectasis, scleroenfizemul lung), otorhinolaryngology (catarrhal and chronic rhinosinusitis with effusion), rheumatic degenerative (cervical, dorsal, lumbar arthrosis, poliarthrosis)

-rheumatic abarticulare (tendinosis, tendomioze, tendoperiostoze, scapulohumeral periarthritis), posttraumatic (posttraumatic joint redori, states after operations the muscles, joints and bones, state after twists, sprains, fractures)-associated (gynecological, endocrine, cardiovascular diseases).

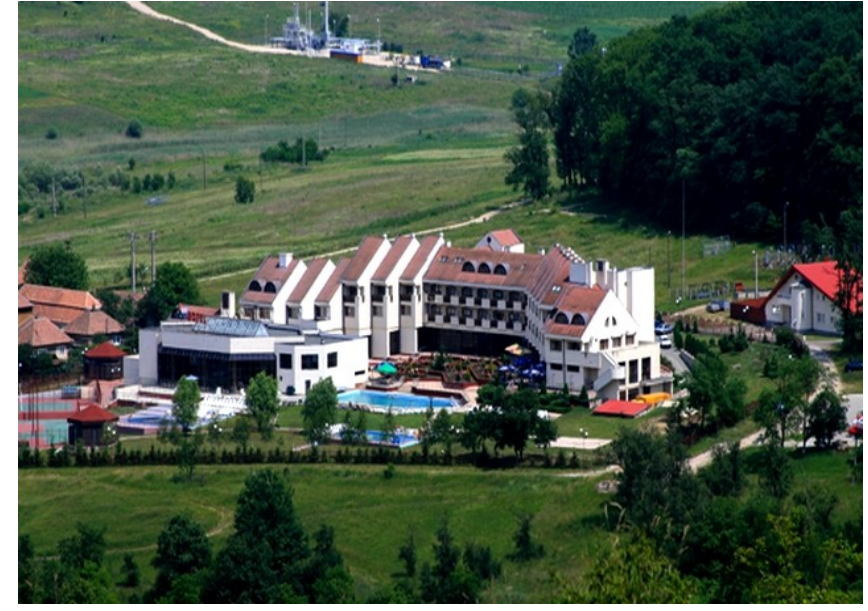

\section{Băile Bazna}

http://www.skytrip.ro

Geographic area: Small Type Tarnava Hills area: hill

basin / river / stream: Bazna

Location: High Hill (599m alt)

\section{External cure:}

-mineral baths and mud procedures for degenerative rheumatic diseases (cervical, dorsal, lumbar arthrosis, poliarthrosis)

-rheumatic inflammatory (allergic state after rheumatic fever or infection after the outbreak), rheumatic abarticulare (tendinosis, tendomioze, tendoperiostoze, scapulohumeral periarthritis

-traumatic (post-traumatic joint redori, states after operations on the joints, muscles and bones, state after twists, sprains and fractures), chronic musculoskeletal disorders (chronic arthritis, spondylitis, arthritis traumatic, painful calluses)

- chronic dermatological (skin disease), peripheral nervous system (state of fatigue, paralysis, traumatic paralysis, sequels after polyneuropathies, sequelae after poliomyelitis poliradiculoneuropatii), endocrine and nutrition (debility in children, rickets), exudative diathesis

-cure king's evil foreign

-vaginal irrigation with warm salt water (38 C - 40 C) for chronic gynecological (ovarian insufficiency, cervicitis, chronic metroanexite)

\section{References}

http://articole.famouswhy.ro/

http://www.inffo.ro

http://e-calauza.ro 